\title{
SMALL SCALE INDUSTRIES IN INDIA: PROSPECTS AND CHALLENGES
}

\author{
*Dr. Anoop Kumar Singh \\ **Puneet Kumar Srivastava \\ *Associate Professor, Department of Applied Economics, Lucknow University, Lucknow \\ **Research Scholar, Department of Applied Economics, Lucknow University, Lucknow
}

\begin{abstract}
Small Scale Industries (SSI) consist entrepreneurs who all are engaged in production, manufacturing or service at micro level. Small industries have been playing a major role in India's economic and social development in the post-independence era. Small scale industries are fundamental to a developing economy with its effective, efficient, flexible and innovative entrepreneurial spirit. SSI units across the world have been approved on the basis of promoters of economic growth and indicative of promoting equitable development. SSI's contribution to the Indian economy in terms of job creation opportunities, reducing regional imbalances, promoting inter-regional linkages, increasing exports and promoting equal economic growth potential has been quite amazing. The sector ranges from traditional to high technology through over 6000 products, comprising over 36 million units across the country, employing over 80 million individuals. SSI helps in the growth of industrial development of the country. This paper attempts to discuss the role of small scale industries in developing the economy and explores various problems faced by it.
\end{abstract}

Keywords: SSI, economic growth, regional imbalances and inter-regional linkages.

\section{Introduction:}

India is primarily an agricultural country. Apart from agriculture, small and large scale industries have also been developed. Small scale industries are the backbone of our industrial infrastructure as they provide a variety of non-traditional, low technology products. They are also engaged in processing, preservation, manufacturing and servicing activities and are playing an important role in balanced and sustainable economic development. Thus, proper development of small scale industries is necessary for the healthy development of the economy. The primary objective of developing small scale industries in rural areas is to generate better employment opportunities, raise the income level and standard of living of the people. Providing ancillary or alternative occupation to small scale industries and use of local labour and raw materials are essential. They facilitate an effective mobilization of capital and skills resources and also encourage the development of industrial entrepreneurship. 


\section{Meaning of Small Scale Industries}

Small scale industries are labour intensive yet require very little capital. Small scale industries having small enterprises and manufacture either goods or provide services with the help of machines and workers.

The enterprise should come under the guidelines set by the Government of India. Small scale industries in India provide many job opportunities for skilled labourers. After all, small industries are necessary for the economy from a financial and social point of view.

For a developing country like India, these industries blossom due to huge demand and opportunity. Some small scale industries are also exporting goods, bringing foreign currencies into India. In India, about half of the products (45-55\%) shipped are from small and medium scale industries. Some small scale industries are created due to the demand of vendors for multinationals.

The Government of India has issued some guidelines for small scale industries in terms of investment of the company and the revenue it generates. Manufacturing / production, ancillary and service industries are included in small scale industries.

- Manufacturing Industries: Units that produce ready-to-use goods or are used in processing industries. These types of small scale industries are typically individually owned. Power looms, engineering industries, food processing etc are mainly examples of manufacturing small scale industry.

- Subsidiary industry: Large companies or MNC manufactures finished goods, but they generally do not make all the parts themselves. The vendors of these companies are ancillary industries. Subsidiary industries can also be identified as companies that make machines for multinational companies or medium scale industries.

- Service industries: Maintenance and repair shops industries fall under the category of service industries.

Apart from this type of industries, there are feeder industries and mining or quarrying. The Central Government on $1^{\text {st }}$ July, 2020 notifies the following criteria for classification of micro, small and medium enterprises, namely:-

The limit for investment in plant and machinery/equipment for manufacturing/service enterprises is shown in Table 1.

Table 1.Classification of Enterprises

\begin{tabular}{|c|c|c|}
\hline \multicolumn{3}{|c|}{$\begin{array}{l}\text { Definition of MSME (w.e.f. } 1^{\text {st }} \text { July,2020) } \\
\text { (Manufacturing and Service Sector) }\end{array}$} \\
\hline Enterprise & Investment(Up to) & Annual Turnover(Up to) \\
\hline Micro & Rs. 1 crore & Rs. 5 crore \\
\hline Small & Rs. 10 crore & Rs. 50 crore \\
\hline Medium & Rs. 50 crore & Rs. 250 crore \\
\hline
\end{tabular}


Industrial units are usually divided into small, medium and large scale units which depend on their size, capital investment and number of human resources. The concept of small business has been defined by different countries in different ways, although the definition changes over time. The criteria adopted in different countries are shown in Table 2.

Table 2. Criteria of Defining Small Business in Various Countries

\begin{tabular}{|l|l|}
\hline Criterion & Countries \\
\hline Employment & USA and UK \\
\hline Investment in Plant and Machinery & India, Pakistan, Indonesis \\
\hline Investment and Employment & Japan, Korea, Phillippines \\
\hline Employment and Sales turnover & Korea(Commerce) \\
\hline Investment and Sales turnover & Malaysia \\
\hline Production/Sales turnover & China, UK(commercial) \\
\hline
\end{tabular}

Source:Gupta C.B.\& Khanka S.S.,' Entrepreneurship and Small Business Management (2010)',Sultan Chand \& Sons, New Delhi, page 2.4

\section{Objective of the Study}

1. To study the importance and needs of small scale industries.

2. To focus on the growth trends and opportunities available for SSI.

3. To review and assess the performance and challenges faced by SSI in India.

\section{Research Methodology}

\section{Types of Research}

The type of research is completely descriptive in nature.

\section{Source of Data}

The secondary data has been collected from various sources such as journals, books, articles, government published annuals reports, website of different government agencies etc.

\section{Statistical tools used}

In order to analyze the growth and performance of SSI the various statistical tools have been analyzed by using average, standard deviation, coefficient of variation and compound annual growth rate.

\section{Literature Review}

Small scale industries have been given an important place in the economy of both developing and developed countries. Economic development of developed countries can be directly linked to growth of small scale industries. The small industrial sector in India has recorded rapid growth. Thus, in the available literature, various aspects of small scale industries have been studied. Such important studies are briefly reviewed here. 
Studies can be classified into four categories which are given as:

\section{i. Studies Examining the General Problems and Prospectus of Small-Scale Units \\ ii. Studies Evaluating the Functional Performance of Institutions Financing SSI Units. \\ iii. Studies Analyzing the Role of Financial Institutions.}

iv. Studies on Sickness of Small-Scale Industries

\section{i. Studies Examining the General Problems and Prospectus of Small-Scale Units}

A study conducted by Bhati (1976) states that in a majority of cases, units outside the industrial estates, showed higher rates of surplus

Rama Swamy (1993) in his study examines three hypothesis regarding small- scale manufacturing units, namely: small firms use more labour per unit of capital, they produce more output per unit of capital and small firms use resources more efficiently than large firms. The analysis indicates that capital intensity and partial productivities are sensitive to alternative measures of firm size. And total factor productivity is not found systematically related.

ii. Studies Evaluating the Functional Performance of Institutions Financing SSI Units. Sandesara (1988) describes the Institutional framework for the small and medium Industries in India. The impact of assistance on firms in this sector and the working of these institutions are also analyzed. He argues for a fresh approach to the institutional set-up and policy framework for this sector.

Rao (1989) makes an enquiry into the functioning of all state Industrial Development Corporations in India with a view to find out to what extend the objectives has been fulfilled. The causes for good and poor performance are also identified.

\section{iii. Studies Analyzing the Role of Financial Institutions.}

Prasad (1995) in his study states that, there has been a steady growth in the flow of Institutional finance to SSI during the last two decade. But inadequate accesses to credit both short term and long term remain a perennial problem of the small-scale sector.

Parag Pandey (2000) in his study emphasis the need for extension of definition of smallscale Industry and revitalizing the law governing small-scale Industry and recommended the setting up of growth centres to provide adequate infrastructure facilities.

\section{iv. Studies on Sickness of Small-Scale Industries}

Reddy (1988) in his study on sickness in small-scale Industry states that the existence of large magnitude of nonviable sick units is a threat to industrial progress; there is an urgent need to review the situation and take remedial measures.

Abraham (1991) reports that the success or failure of any small enterprise depends mainly on the entrepreneur, support system and the environment. He stressed that-the success or failure is determined mostly by the human element involved in industrial enterprise. 


\section{Analysis and Interpretation}

Table.3 Performance of Small Scale Industries

\begin{tabular}{|l|l|l|}
\hline Year & No. of Units in Lakhs & \% Change in no. of units \\
\hline $2000-2001$ & 101.1 & \\
\hline $2001-2002$ & 105.21 & 4.06 \\
\hline $2002-2003$ & 109.49 & 4.06 \\
\hline $2003-2004$ & 113.95 & 4.07 \\
\hline $2004-2005$ & 118.59 & 4.07 \\
\hline $2005-2006$ & 123.42 & 4.07 \\
\hline $2006-2007$ & 261.01 & 111.48 \\
\hline $2007-2008$ & 272.79 & 4.51 \\
\hline $2008-2009$ & 285.16 & 4.53 \\
\hline $2009-2010$ & 298.10 & 4.53 \\
\hline $2010-2011$ & 428.73 & 43.82 \\
\hline $2011-2012$ & 447.64 & 4.41 \\
\hline $2012-2013$ & 467.54 & 4.44 \\
\hline $2013-2014$ & 488.46 & 4.47 \\
\hline $2014-2015$ & 510.57 & 4.52 \\
\hline $2015-2016$ & 549.58 & 24.15 \\
\hline $2016-2017$ & 583.85 & 6.23 \\
\hline $2017-2018$ & 618.11 & 5.86 \\
\hline $2018-2019$ & 652.38 & 5.54 \\
\hline $2019-2020$ & 686.65 & 5.25 \\
\hline AVG & $\mathbf{3 6 1 . 1 1}$ & $\mathbf{1 3 . 3 7}$ \\
\hline STD & $\mathbf{2 0 5 . 7 4}$ & $\mathbf{2 5 . 6 9}$ \\
\hline CV & $\mathbf{5 6 . 9 7}$ & $\mathbf{1 9 2 . 1 4}$ \\
\hline CAGR & $\mathbf{1 0 . 6 1}$ & $\mathbf{1 . 3 6}$ \\
\hline
\end{tabular}

Source: MSME Annual Report

Fig.1 No. of Small Scall Industries in Lakhs

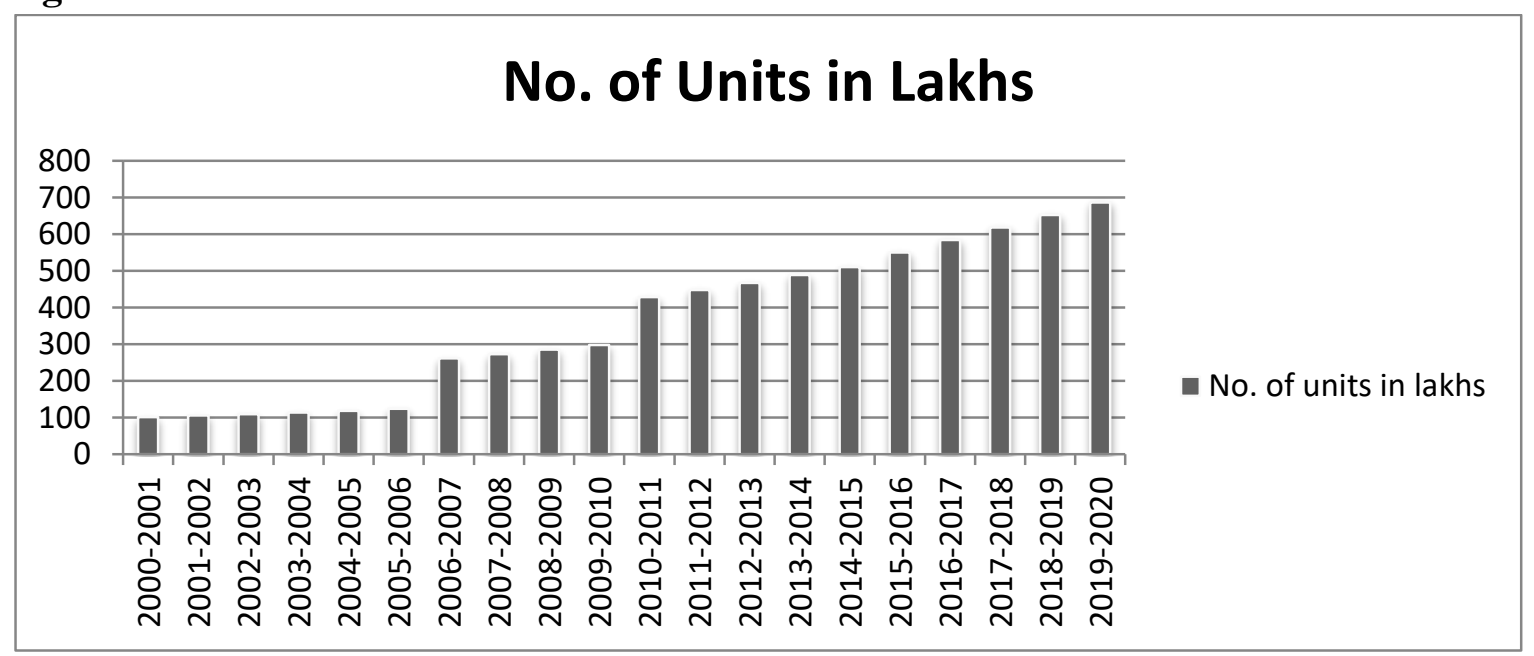


Table 3 above shows the performance of SSI in terms of number of units during 2001-2019. From the table the number of SSIs have increased from 105.21 lakhs in 2001-2002 to 686.65 lakhs in 2019-2020. This shows that SSI has progressed during the study period. The average number of registered units is 361.11 lakhs. The annual growth rate in the year 2018-2019 is 5.54 which decreased to 5.29 in the year 2019-2020. The average percentage of change in no. of units is 13.37. The standard deviation of units is less than the average value of registered units. The compound annual growth rate is 10.61 and the coefficient of variation is 56.97.

Table.4 Performance of SSIs by Fixed Assets Investment

\begin{tabular}{|l|l|l|}
\hline Year & Investment in Crores & \% Annual Increase \\
\hline $2000-2001$ & 127279 & \\
\hline $2001-2002$ & 154389 & 21.29 \\
\hline $2002-2003$ & 162317 & 5.13 \\
\hline $2003-2004$ & 170219 & 4.86 \\
\hline $2004-2005$ & 178699 & 4.98 \\
\hline $2005-2006$ & 188113 & 5.26 \\
\hline $2006-2007$ & 500758 & 166.20 \\
\hline $2007-2008$ & 558190 & 11.46 \\
\hline $2008-2009$ & 621753 & 11.38 \\
\hline $2009-2010$ & 693835 & 11.59 \\
\hline $2010-2011$ & 1105934 & 59.39 \\
\hline $2011-2012$ & 1182757 & 6.94 \\
\hline $2012-2013$ & 1268763 & 7.27 \\
\hline $2013-2014$ & 1363700 & 7.48 \\
\hline $2014-2015$ & 1471912 & 7.93 \\
\hline $2015-2016$ & 1525093 & 3.61 \\
\hline $2016-2017$ & 1635325 & 7.22 \\
\hline $2017-2018$ & 1745556 & 6.74 \\
\hline $2018-2019$ & 1855788 & 6.31 \\
\hline $2019-2020$ & 1966019 & 5.93 \\
\hline AVG & $\mathbf{9 2 3 8 2 0}$ & $\mathbf{1 8 . 9 9}$ \\
\hline STD & $\mathbf{6 5 4 4 7 6}$ & $\mathbf{3 7 . 7 4}$ \\
\hline CV & $\mathbf{7 0 . 8 4}$ & $\mathbf{1 9 8 . 7 3}$ \\
\hline CAGR & $\mathbf{1 5 . 5}$ & $\mathbf{- 6 . 5 1}$ \\
\hline SOure: & \\
\hline
\end{tabular}

Source: MSME Annual Report 
Fig.2 Small Scale Industries Investment in Crores

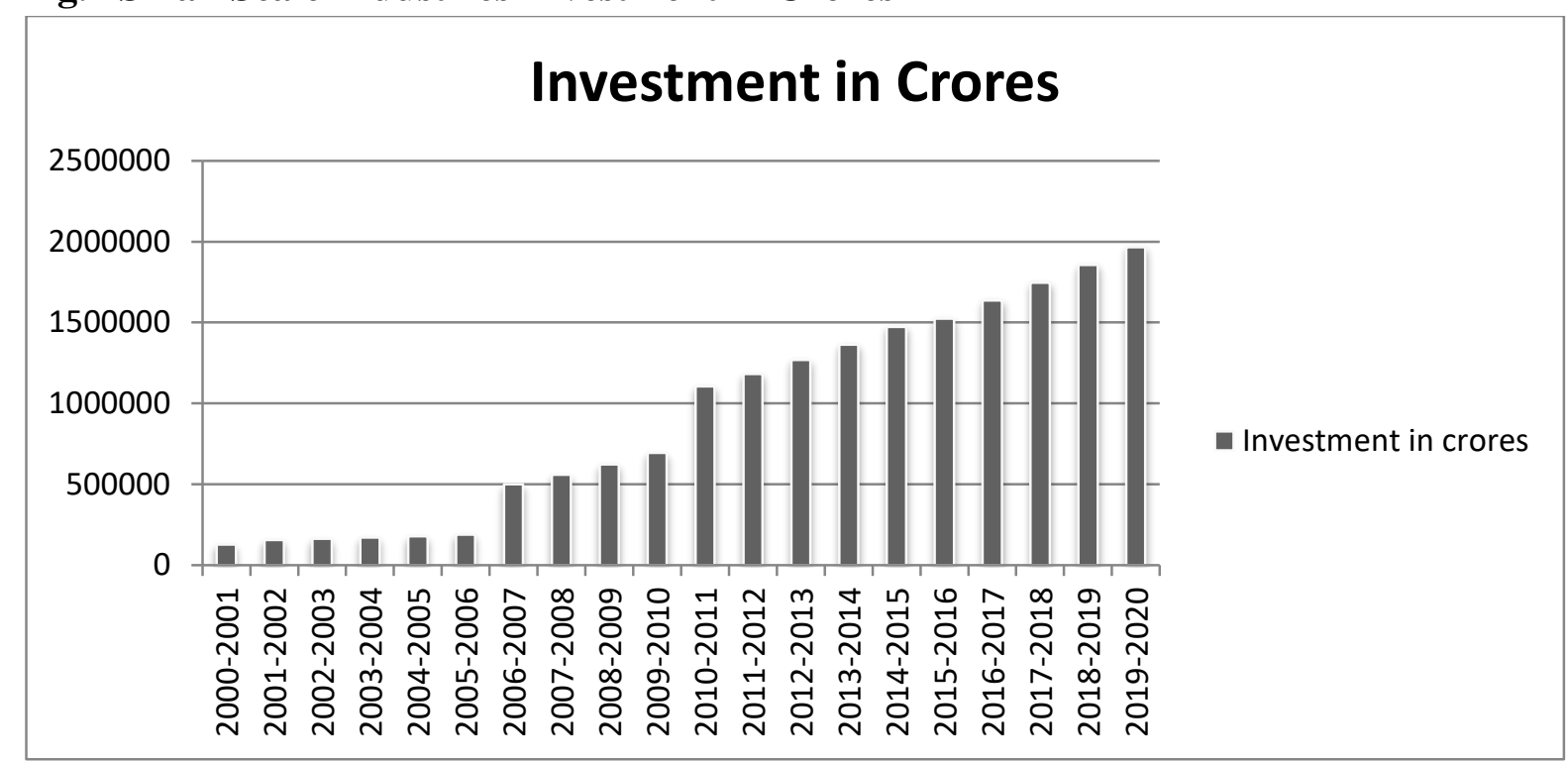

It is clear from the Table 4 that small scale industry has invested Rs 19,66,019 crores during 2019-20.The average percentage of annual increase in investment is 17.52 . There seems to be a growing trend of investment in small scale industries. The standard deviation is less than the average value of the investment, indicating that the investment volatility in the sector during this period is low. The compound annual growth rate is 15.5 which is higher than the compound annual growth rate of the number of registered units.

Table.5 Performance of Small Scale Industries with Respect to Employment

\begin{tabular}{|l|l|l|}
\hline Year & Employment No. in Lakhs & \% Annual Increase \\
\hline $2000-2001$ & 238.73 & \\
\hline $2001-2002$ & 249.33 & 4.44 \\
\hline $2002-2003$ & 260.21 & 4.36 \\
\hline $2003-2004$ & 271.42 & 4.30 \\
\hline $2004-2005$ & 282.57 & 4.10 \\
\hline $2005-2006$ & 294.91 & 4.36 \\
\hline $2006-2007$ & 595.16 & 101.81 \\
\hline $2007-2008$ & 626.34 & 5.23 \\
\hline $2008-2009$ & 659.35 & 5.27 \\
\hline $2009-2010$ & 695.38 & 5.46 \\
\hline $2010-2011$ & 732.17 & 5.29 \\
\hline $2011-2012$ & 882.76 & 20.56 \\
\hline $2012-2013$ & 956.05 & 8.30 \\
\hline $2013-2014$ & 1029.34 & 7.66 \\
\hline $2014-2015$ & 1102.63 & 7.12 \\
\hline $2015-2016$ & 1175.91 & 6.64 \\
\hline $2016-2017$ & 1249.20 & 6.23 \\
\hline $2017-2018$ & 1322.49 & 5.86 \\
\hline $2018-2019$ & 1395.78 & 5.54 \\
\hline
\end{tabular}




\begin{tabular}{|l|l|l|}
\hline $2019-2020$ & 1469.07 & 5.25 \\
\hline AVG & $\mathbf{7 7 4 . 4 4}$ & $\mathbf{1 1 . 4 6}$ \\
\hline STD & $\mathbf{4 2 3 . 0 4}$ & $\mathbf{2 2 . 1 7}$ \\
\hline CV & $\mathbf{5 4 . 6 2}$ & $\mathbf{1 9 3 . 4 5}$ \\
\hline CAGR & $\mathbf{1 0 . 0 4}$ & $\mathbf{0 . 8 9}$ \\
\hline
\end{tabular}

Source: MSME Annual Report

Fig.3 Small Scale Industries Employment No. in lakhs

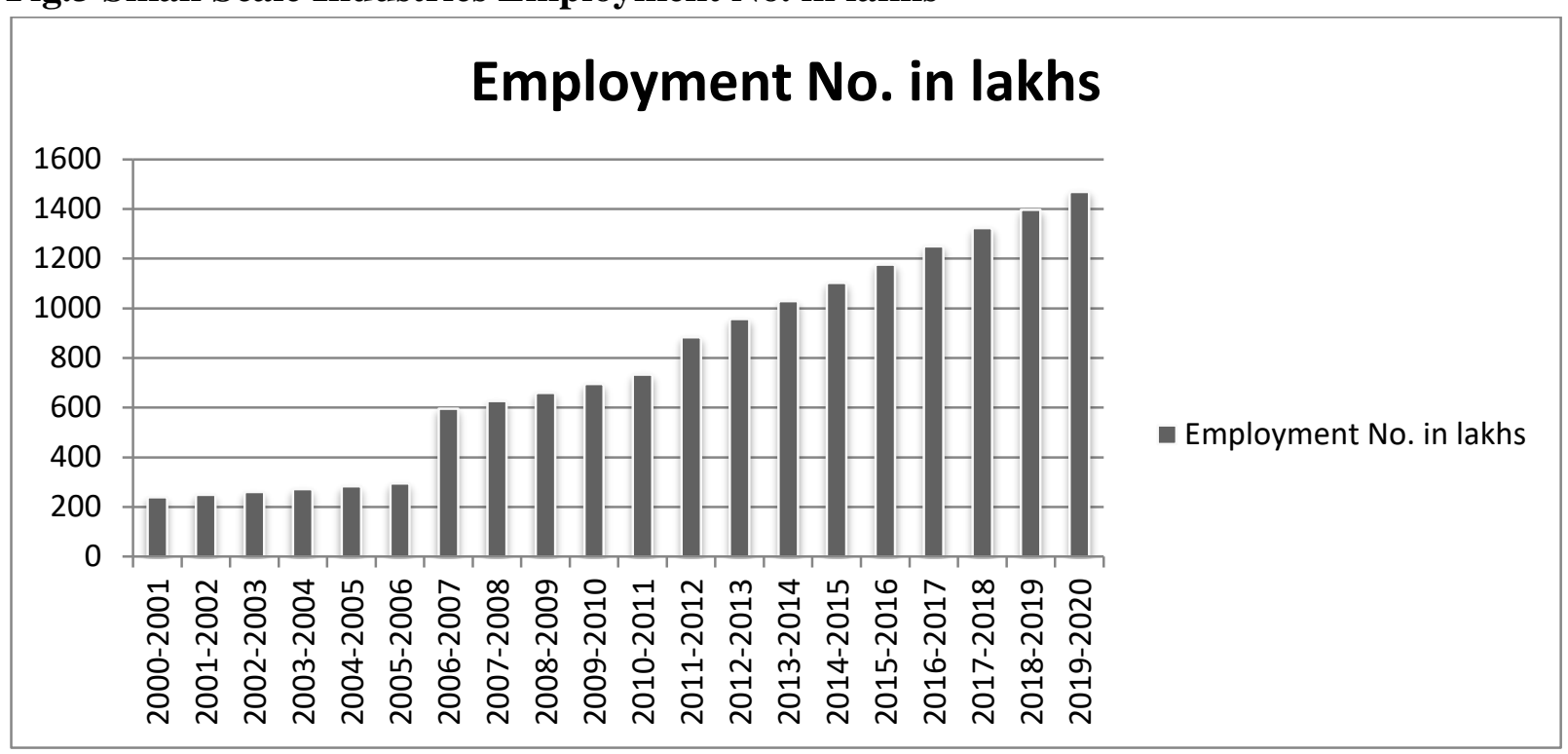

It is clear from the Table $\mathbf{5}$ that the small scale sector is playing an important role in increasing employment in the economy. The employment generation of this sector during 2001-2002 is Rs.249.33 lakhs. The employment has increased to 1469.07 lakhs by 20192020. The average percentage of annual increase in employment is Rs.11.46 lakhs. The average employment is Rs.774.44 lakhs and standard deviation is Rs.423.04. The compound annual growth rate is 10.04 .

\section{Conclusion}

The small scale sector is playing an important role in the growth of the economy due to its excellent performance. The government took several measures to encourage this sector. The sector has faced challenges due to liberalization including intense competition from global players in marketing their products, opportunities such as technology, outsourcing by large industries and so on. The average number of registered units during the period of study is 361.11. The average investment is Rs.923820 crores. The average employment provided by this sector is Rs.774.44 lakhs. Volatility in relation to no. of units, investment and employment is low because the average value is higher than the standard deviation. The risk associated with this sector is low, it has been suggested that greater concentration in this sector will lead to more development. The performance of the small scale sector is progressive during 2001-2019. 


\section{References}

1. Government of India-Annual Report (2011-2012) Ministry of Micro, Small and Medium Enterprise, New Delhi.

2. Report on Prime Minister Task Force on Micro, Small and Medium Enterprise (2010), Ministry of Micro, Small and Medium Enterprise, New Delhi.

3. www.rbi.org.in

4. MSME Annual Report 2011-2012 and 2013-2014.

5. MSME at a glance 2016, Govt. of India.

6. www.msme.gov.in

7. Reserve Bank of India, Annual Report from 2001 to 2012. 